\title{
COVID-19 Vaccination Behavior of People Living with HIV: The Mediating Role of Perceived Risk and Vaccination Intention
}

\author{
Li Qi ${ }^{1,2}{ }^{\oplus}$, Li Yang ${ }^{3}$, Jie Ge ${ }^{4}$, Lan $\mathrm{Yu}^{5}$ and Xiaomei $\mathrm{Li}^{1, *}$ \\ 1 School of Nursing, Health Science Centre, Xi'an Jiaotong University, Xi'an 710049, China; liqi@qmu.edu.cn \\ 2 School of Nursing, Qiqihar Medical University, Qiqihar 161006, China \\ School of Nursing, Qingdao University, Qingdao 266073, China; yangli81@qdu.edu.cn \\ 4 School of Public Health, Qiqihar Medical University, Qiqihar 161006, China; gejie@qmu.edu.cn \\ 5 AIDS and STD Institute, Heilongjiang Center for Disease Control and Prevention, Harbin 150030, China; \\ lanyu200406@yahoo.com \\ * Correspondence: roselee@xjtu.edu.cn; Tel.: +86-29-82657017
}

Citation: Qi, L.; Yang, L.; Ge, J.; Yu, L.; Li, X. COVID-19 Vaccination Behavior of People Living with HIV: The Mediating Role of Perceived Risk and Vaccination Intention. Vaccines 2021, 9, 1288. https://doi.org/ $10.3390 /$ vaccines 9111288

Academic Editor: Vincenzo Baldo

Received: 28 September 2021

Accepted: 3 November 2021

Published: 6 November 2021

Publisher's Note: MDPI stays neutral with regard to jurisdictional claims in published maps and institutional affiliations.

Copyright: (c) 2021 by the authors. Licensee MDPI, Basel, Switzerland. This article is an open access article distributed under the terms and conditions of the Creative Commons Attribution (CC BY) license (https:/ / creativecommons.org/licenses/by/ $4.0 /)$.

\begin{abstract}
The COVID-19 vaccination behavior of people living with HIV (PLWH) was examined via a cross-sectional web-based survey of PLWH aged 18 years and older. The survey was conducted from 1 May to 20 June 2021. The survey included social demographic information; vaccination behavior (B); and questions related to perceived usefulness (PU), perceived risk (PR), subjective norms (SNs), perceived behavior control (PBC), and behavior intention (BI). The associations between the questionnaire variables and COVID-19 vaccination behavior were assessed by calculating the descriptive data, correlation analysis, and structural equation modeling. In total, $43.71 \%$ of the 350 eligible respondents had received a COVID-19 vaccine. The differences in COVID-19 vaccination behavior according to age, gender, religious belief, marital status, income, education level, and occupation were not obvious $(p>0.05)$. PU had a significantly negative effect on PR $(p<0.05)$. PR had a significantly negative effect on BI $(p<0.05)$. SNs had a significantly positive effect on BI $(p<0.05)$. $\mathrm{BI}$ had a significantly positive effect on B $(p<0.05)$. PR fully mediated the effects of PU on BI, BI fully mediated the effects of PR on B, and BI fully mediated the effects of SNs on B $(p<0.05)$. Health policymakers and medical workers should provide more information about the risks of vaccine application to improve the vaccination behavior of PLWH.
\end{abstract}

Keywords: people living with HIV; COVID-19 vaccination behavior; perceived risk; behavioral intention; mediating role

\section{Introduction}

The global epidemic of coronavirus disease 2019 (COVID-19) is the most widespread and influential public health event of recent years [1-4]. The global data available from the WHO website on 9 July 2021 reported 185,038,806 confirmed COVID-19 cases and 4,006,882 deaths [5]. Vaccination is one of the most effective and cost-effective health measures that can be used to prevent COVID-19 [6-8]. Efficient COVID-19 vaccination delivery with a high population coverage is the only foreseeable means of generating herd immunity and controlling and preventing COVID-19 [9-12].

On 29 March, the National Health Commission of the People's Republic of China issued the "Technical Vaccination Recommendations for COVID-19 Vaccines in China (First Edition)" [13], which cleared the COVID-19 vaccine for administration to people aged 18 and above and provided vaccination suggestions for people aged 60 and above, chronic disease patients, etc. The guidelines recommended that chronic disease patients with stable health and good drug control should be vaccinated voluntarily after weighing the advantages and disadvantages. However, there are no data on the safety and efficacy of the COVID-19 vaccine for people living with human immunodeficiency virus (HIV)/acquired 
immunodeficiency syndrome (AIDS) (PLWHA). People living with HIV (PLWH) account for approximately $0.5 \%$ of the global population $[14,15]$. The vaccination of PLWH also affects vaccine coverage. Some scholars believe that PLWH should improve their vaccination rate as soon as possible [16]. Because there are not enough data on the effects of and adverse reactions to the vaccine among PLWH, their vaccination attitudes will affect their vaccination behavior.

The aim of this study was to establish a theoretical model that explains the mediating effect of vaccination intention regarding the COVID-19 vaccine on the vaccination behavior of PLWH in China by developing a structural equation model that comprehensively demonstrates the correlations among the influencing factors. Our findings provide basic data for developing COVID-19 vaccine education programs and interventions targeting vaccine hesitancy among PLWH.

\section{Literature Review and Research Hypotheses}

Rahimi et al. $[17,18]$ contended that the user's subjective perceived usefulness (PU) and perceived ease of use (PE) affect their behavioral intention (BI) and behavior (B). The concept of perceived risk (PR) was originated in the field of psychology by Bauer of Harvard University. He believed that the purchase behavior of consumers may not be able to indicate whether the expected results are correct, and some results may make consumers unhappy. Therefore, uncertainty about the results is implicit in consumers' purchase decisions $[19,20]$. Ajzen found that people's behavior is not completely voluntary but is under control. Behavior attitude, subjective norms (SNs), and perceived behavior control (PBC) together affect BI, while BI and PBC affect actual behavior (B) [21-23]. The PE for the COVID-19 vaccine mainly depends on the time, place, and price of the vaccination. At present, in order to speed up the process of vaccination, China has set up many vaccination stations providing free vaccinations. In some places, in order to facilitate the vaccination of residents, vaccinations are carried out at the workplace, where residents gather relatively frequently. Therefore, this study did not consider PE. To examine the influences on B, we set up the following research framework (see Figure 1) and research hypotheses.

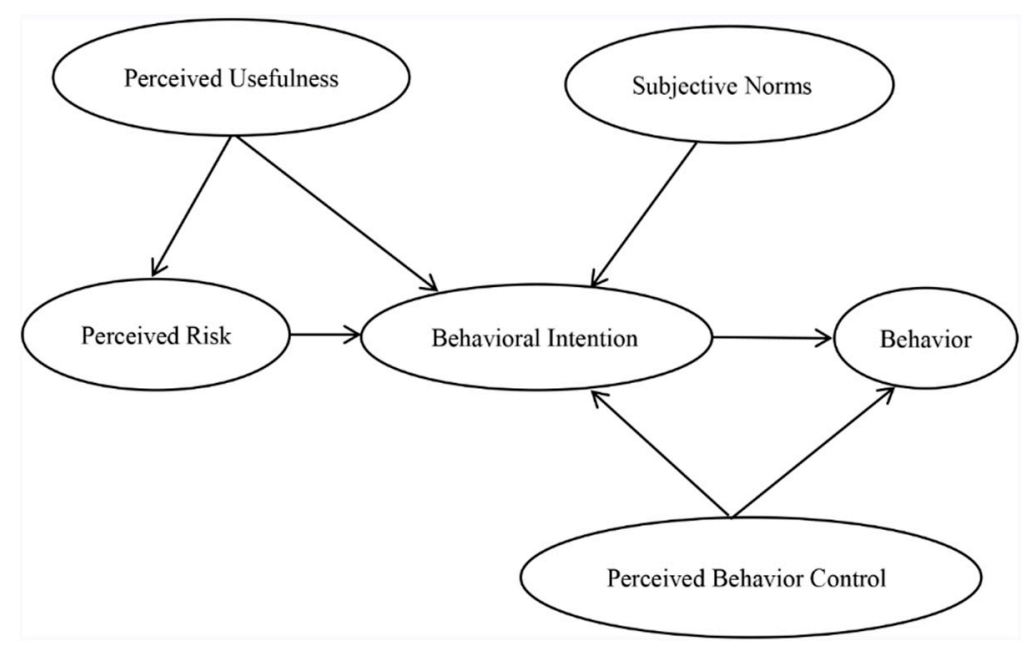

Figure 1. The research framework.

Hypothesis 1 (H1). PU exerts a negative effect on PR.

Hypothesis 2 (H2). PU exerts a positive effect on BI.

Hypothesis 3 (H3). PR exerts a negative effect on BI.

Hypothesis 4 (H4). SN exerts a positive effect on BI. 
Hypothesis 5 (H5). PBC exerts a positive effect on BI.

Hypothesis 6 (H6). PBC exerts a positive effect on $B$.

Hypothesis 7 (H7). BI exerts a positive effect on B.

\section{Methods}

\subsection{Study Design}

We conducted a cross-sectional anonymous web-based survey using an electronic questionnaire, distributed via online social platforms (WeChat and QQ) among PLWH (i.e., PLWH who were 18 years or older and had good drug control). The survey was conducted between 1 May and 20 June 2021. When PLWH came for antiretroviral treatment (ART) drugs and a physical examination, they scanned the QR code of the questionnaire and then filled in the questionnaire. At the same time, we also used the snowball method to spread and distribute the questionnaire among PLWH.

Before we presented the questionnaire to PLWH, the questionnaire was pilot-tested by a panel of experts in related fields, including an expert in infectious diseases, a behavioral psychologist, an epidemiologist, and a statistician. Specifically, the experts proofread the questionnaire and ascertained its content validity in terms of the fit between each statement in the questionnaire and the corresponding theoretical variable. The questionnaire was then amended according to the suggestions for revision made by the experts.

\subsection{Questionnaire}

The questionnaire consisted of the following sections: (1) sociodemographic predictor variables, which included age, gender, religious belief, marital status, income, education level, and occupation; HIV related characteristics, which included duration of diagnosis, chronic disease, virus load detection, and the side effects of antiretroviral drugs; (2) perceived usefulness (PU), perceived risk (PR), subjective norms (SNs), perceived behavior control (PBC), and vaccination behavioral intention (BI) regarding the COVID-19 vaccine (see Table 1 for details); (3) and COVID-19 vaccination behavior (B). The questionnaire included 31 questions and generally took less than $10 \mathrm{~min}$ to complete.

\subsection{Variables and Measurements}

PU, PR, SNs, PBC, and BI were scored on a 5-point Likert scale, with a score of 1 indicating strong disagreement and a score of 5 indicating strong agreement. B was transformed to a binary variable $(1=$ yes and $0=$ no $)$ in order to facilitate analysis.

\subsection{Reliability of the Questionnaire}

Cronbach's alpha internal reliability method produced a figure of 0.858 for the internal consistency of our research, which showed that this study instrument was valid and reliable for data-gathering activities.

\subsection{Statistical Analysis}

The software packages SPSS 23.0 and Analysis of Moment Structures (AMOS) 20.0 were used for statistical analysis. Calculation of the descriptive data, correlation analysis, and structural equation modeling (SEM) were conducted. A $p$-value of $<0.05$ was considered statistically significant.

\subsection{Ethical Considerations}

This study was approved by the Ethics and Research Review Committee of Qiqihar Medical University ([2020]38). 
Table 1. PU, PR, SN, PBC, and BI.

\begin{tabular}{|c|c|}
\hline Research Constructs & Measurement Items \\
\hline PU & $\begin{array}{l}\text { 1. You think the COVID-19 vaccine can prevent COVID-19. } \\
\text { 2. You think it's easier to get COVID-19 without vaccination. } \\
\text { 3. You think vaccination can benefit you. } \\
\text { 4. You think vaccination can benefit others. }\end{array}$ \\
\hline PR & $\begin{array}{l}\text { 1. You think the COVID-19 vaccine is safe. } \\
\text { 2. You think the COVID-19 vaccine will have side effects. } \\
\text { 3. You think you can be infected with COVID-19, even if you have been vaccinated. } \\
\text { 4. You think not vaccinating will have an impact on the people around you. }\end{array}$ \\
\hline $\mathrm{SN}$ & $\begin{array}{l}\text { 1. The people around you have been vaccinated. } \\
\text { 2. Your family supports your vaccination. } \\
\text { 3. You accept your family's advice regarding the COVID-19 vaccination. } \\
\text { 4. You accept your friends' advice regarding the COVID-19 vaccination. } \\
\text { 5. You accept medical workers' advice regarding the COVID-19 vaccination. } \\
\text { 6. You accept the government's advice regarding the COVID-19 vaccination. } \\
\text { 7. You accept the suggestions of media publicity regarding the COVID-19 vaccination. } \\
\text { 8. You will get vaccinated after a lot of people have been vaccinated. }\end{array}$ \\
\hline PBC & $\begin{array}{l}\text { 1. You can decide for yourself to get vaccinated. } \\
\text { 2. You can choose your own type of vaccine. } \\
\text { 3. You can choose your own time for the vaccine. } \\
\text { 4. You can choose your own place for the vaccine. }\end{array}$ \\
\hline BI & $\begin{array}{l}\text { 1. You would like to be vaccinated. } \\
\text { 2. You support the application of vaccines in PLWH. } \\
\text { 3. You will recommend vaccinations to others. }\end{array}$ \\
\hline
\end{tabular}

\section{Results}

\subsection{Intention to Get Vaccinated, Vaccination Status, and Participant Characteristics}

Overall, 350 respondents completed the survey, 95.7\% of whom were male $(n=335)$. The age (mean \pm SD) of the respondents was $36.01 \pm 9.64$ years. Of these, $88.3 \%$ had no religious beliefs $(n=309) ; 76.6 \%$ were single $(n=268) ; 70.9 \%$ had an income below RMB $5000(n=248)$; and $57.7 \%$ had a college degree, a bachelor's degree, or above $(n=202)$. In total, $6.0 \%$ were medical-related majors $(n=21)$, while $55.1 \%$ were service trade staff $(n=193)$. The differences according to age, gender, religious belief, marital status, income, education level, and occupation were not statistically significant $(p>0.05)$. Among the respondents, $64.0 \%(n=224)$ had been diagnosed with an HIV infection for less than five years, and $19.4 \%(n=68)$ had been diagnosed with other chronic diseases. In total, 189 respondents knew their viral load results; of these, $95.2 \%(n=180)$ did not detect the viral load. After taking antiretroviral drugs, $6.0 \%(n=21)$ of the respondents had no side effects, $80.6 \%(n=282)$ had mild side effects, and $13.4 \%(n=47)$ had moderate side effects. The differences in the duration of diagnosis, the presence of other chronic diseases, the virus load detection, and the side effects of antiretroviral drugs were not statistically significant $(p>0.05)$ (see Tables 2 and 3 for details).

\subsection{The SEM Fitting Index Results}

The chi-square/degrees of freedom $\left(\chi^{2} / \mathrm{DF}\right)$ and root mean square error of approximation (RMSEA) were used to test the fitness of the SEM, where $1<\chi^{2} / \mathrm{DF}<3$ and RMSEA $<0.05$ indicate a better fit [24,25]. The Tucker-Lewis index (TLI) and the comparative fit index (CFI) were the incremental fit indices, where TLI $>0.95$ and CFI $>0.95$ indicate a very good fit [26]. In our study, the $\chi^{2} / \mathrm{DF}$ was 1.318 , the RMSEA was 0.031 , the TLI was 0.961 , and the CFI was 0.964 . Therefore, the overall fit of this research model was acceptable. 


\subsection{Model Analysis Results}

The path analysis results revealed that PU had a significantly negative effect on PR, thus supporting H1. PR had a significantly negative effect on BI, thus supporting H3. SNs had a significantly positive effect on $\mathrm{BI}$, thus supporting $\mathrm{H} 4$. BI had a significantly positive effect on B, thus supporting H6. The hypothesis test results are presented in Table 4. The results of deleting meaningless paths are shown in Figure 2.

Table 2. Characteristics of participants by intention to get vaccinated and vaccination behavior against COVID-19 $(n=350)$.

\begin{tabular}{|c|c|c|c|c|c|c|c|}
\hline & \multirow[b]{2}{*}{$\begin{array}{l}\text { All Subjects } \\
\begin{array}{c}(n=350) \\
\mathrm{N}(\%)\end{array}\end{array}$} & \multicolumn{3}{|c|}{ Intention to Get Vaccinated Against COVID-19 } & \multicolumn{3}{|c|}{ COVID-19 Vaccination Behavior } \\
\hline & & $\begin{array}{l}\text { Intend to Get } \\
\text { Vaccinated } \\
(n=280) \\
\mathrm{N}(\%)\end{array}$ & $\begin{array}{c}\text { Do Not Intend } \\
\text { to Get } \\
\text { Vaccinated } \\
(n=70) \\
\mathrm{N}(\%)\end{array}$ & $p$-Value & $\begin{array}{l}\text { Vaccinated } \\
\begin{array}{c}(n=153) \\
\mathrm{N}(\%)\end{array}\end{array}$ & $\begin{array}{c}\text { Do Not } \\
\text { Vaccinate } \\
(n=197) \\
\mathrm{N}(\%)\end{array}$ & $p$-Value \\
\hline \multicolumn{8}{|l|}{ Sociodemographic } \\
\hline Gender & & & & 0.741 & & & 0.174 \\
\hline Male & $335(95.7)$ & $269(80.3)$ & $66(19.7)$ & & $149(44.5)$ & $186(55.5)$ & \\
\hline Female & $15(4.3)$ & $11(73.3)$ & $4(26.7)$ & & $4(26.7)$ & $11(73.3)$ & \\
\hline Age group & & & & 0.648 & & & 0.198 \\
\hline $18-20$ & $4(1.1)$ & $4(100.0)$ & $0(0.0)$ & & $3(75.0)$ & $1(25.0)$ & \\
\hline $21-30$ & $110(31.5)$ & $88(80.0)$ & $22(20.0)$ & & $48(43.6)$ & $62(56.4)$ & \\
\hline $31-40$ & $141(40.3)$ & $108(76.6)$ & $33(23.4)$ & & $60(42.6)$ & $81(57.4)$ & \\
\hline $41-50$ & $64(18.3)$ & $55(85.9)$ & $9(14.1)$ & & $33(51.6)$ & $31(48.4)$ & \\
\hline $51-60$ & $27(7.7)$ & $22(81.5)$ & $5(18.5)$ & & $9(33.3)$ & $18(66.7)$ & \\
\hline $61+$ & $4(1.1)$ & $3(75.0)$ & $1(25.0)$ & & $0(0.0)$ & $4(100.0)$ & \\
\hline Religious belief & & & & 0.454 & & & 0.718 \\
\hline Religious belief & $41(11.7)$ & $31(75.6)$ & $10(24.4)$ & & 19(46.3) & $22(53.7)$ & \\
\hline No religious belief & $309(88.3)$ & $249(80.6)$ & $60(19.4)$ & & $134(43.4)$ & $175(56.6)$ & \\
\hline Marital status & & & & 0.900 & & & 0.328 \\
\hline Single & $268(76.6)$ & 214(79.9) & $54(20.1)$ & & $121(45.1)$ & $147(54.9)$ & \\
\hline Married & $82(23.4)$ & $66(80.5)$ & $16(19.5)$ & & $32(39.0)$ & $50(61.0)$ & \\
\hline Income & & & & 0.852 & & & 0.610 \\
\hline$\leq 3000$ & 141(40.3) & $111(78.7)$ & $30(21.3)$ & & $57(40.4)$ & $84(59.6)$ & \\
\hline $30 \overline{0} 1-5000$ & $107(30.6)$ & $85(79.4)$ & $22(20.6)$ & & $46(43.0)$ & $61(57.0)$ & \\
\hline $5001-10,000$ & $74(21.1)$ & $60(81.1)$ & $14(18.9)$ & & $36(48.6)$ & $38(51.4)$ & \\
\hline$>10,000$ & $28(8.0)$ & $24(85.7)$ & $4(14.3)$ & & $14(50.0)$ & $14(50.0)$ & \\
\hline Educational level & & & & 0.439 & & & 0.944 \\
\hline Junior high school and below & $87(24.9)$ & $70(80.5)$ & $17(19.5)$ & & $36(41.4)$ & $51(58.6)$ & \\
\hline $\begin{array}{l}\text { High school or polytechnic } \\
\text { school }\end{array}$ & 61(17.4) & $46(75.4)$ & 15(24.6) & & $26(42.6)$ & $35(57.4)$ & \\
\hline College or bachelor degree & $186(53.1)$ & $149(80.1)$ & $37(19.9)$ & & $84(45.2)$ & $102(54.8)$ & \\
\hline Master degree or above & $16(4.6)$ & $15(93.8)$ & $1(6.3)$ & & $7(43.8)$ & $9(56.3)$ & \\
\hline Occupation & & & & 0.130 & & & 0.742 \\
\hline Medical-related majors & $21(6.0)$ & $15(71.4)$ & $6(28.6)$ & & $10(47.6)$ & $11(52.4)$ & \\
\hline Staff of relevant government & $50(14.3)$ & $45(90.0)$ & $5(10.0)$ & & $26(52.0)$ & $24(48.0)$ & \\
\hline Worker & $55(15.7)$ & $45(81.8)$ & $10(18.2)$ & & $24(43.6)$ & $31(56.4)$ & \\
\hline Farmer & $31(8.9)$ & $21(67.7)$ & $10(32.3)$ & & $13(41.9)$ & $18(58.1)$ & \\
\hline $\begin{array}{l}\text { Service trades staff } \\
\text { HIV related } \\
\text { characteristics }\end{array}$ & 193(55.1) & $154(79.8)$ & $39(20.2)$ & & $80(41.5)$ & $113(58.5)$ & \\
\hline Duration of diagnosis & & & & 0.126 & & & 0.857 \\
\hline$\leq 5$ years & $224(64.0)$ & $185(82.6)$ & $39(17.4)$ & & $100(44.6)$ & $124(55.4)$ & \\
\hline 6-10 years & $98(28.0)$ & $74(75.5)$ & $24(24.5)$ & & $41(41.8)$ & $57(58.2)$ & \\
\hline $11-15$ years & $19(5.4)$ & $13(68.4)$ & $6(31.6)$ & & $9(47.4)$ & $10(52.6)$ & \\
\hline $16-20$ years & $7(2.0)$ & $7(100.0)$ & $0(0.0)$ & & $3(42.9)$ & $4(57.1)$ & \\
\hline$>20$ years & $2(0.6)$ & $1(50.0)$ & $1(50.0)$ & & $0(0.0)$ & $2(100.0)$ & \\
\hline Chronic Disease & & & & 0.418 & & & 0.119 \\
\hline Chronic disease & $68(19.4)$ & $52(76.5)$ & $16(23.5)$ & & $24(35.3)$ & $44(64.7)$ & \\
\hline No chronic disease & $282(80.6)$ & $228(80.9)$ & $54(19.1)$ & & $129(45.7)$ & $153(54.3)$ & \\
\hline $\begin{array}{c}\text { The side effect of anti-retroviral } \\
\text { drugs }\end{array}$ & & & & 0.201 & & & 0.091 \\
\hline No side effects & $21(6.0)$ & $19(90.5)$ & $2(9.5)$ & & $14(66.7)$ & $7(33.3)$ & \\
\hline Mild side effects & $282(80.6)$ & $227(80.5)$ & $55(19.5)$ & & $119(42.2)$ & $163(57.8)$ & \\
\hline Moderate side effects & $47(13.4)$ & $34(72.3)$ & $13(27.7)$ & & $20(42.6)$ & $27(57.4)$ & \\
\hline
\end{tabular}

Note: Mild side effects can be eliminated without special treatment; moderate side effects can be controlled by symptomatic treatment. 
Table 3. Viral load by intention to get vaccinated and vaccination behavior against COVID-19 $(n=189)$.

\begin{tabular}{|c|c|c|c|c|c|c|c|}
\hline \multirow[b]{2}{*}{ Viral Load } & \multirow[b]{2}{*}{$\begin{array}{l}\text { All Subjects } \\
\qquad \begin{array}{c}(n=189) \\
\mathrm{N}(\%)\end{array}\end{array}$} & \multicolumn{3}{|c|}{$\begin{array}{l}\text { Intention to Get Vaccinated against } \\
\text { COVID-19 }\end{array}$} & \multicolumn{3}{|c|}{ COVID-19 Vaccination Behavior } \\
\hline & & $\begin{array}{l}\text { Intend to Get } \\
\text { Vaccinated } \\
(n=136) \\
\mathrm{N}(\%)\end{array}$ & $\begin{array}{c}\text { Do Not Intend } \\
\text { to Get } \\
\text { Vaccinated } \\
(n=53) \\
\mathrm{N}(\%)\end{array}$ & $p$-Value & $\begin{array}{l}\text { Vaccinated } \\
\begin{array}{c}(n=77) \\
\mathrm{N}(\%)\end{array}\end{array}$ & $\begin{array}{c}\text { Do Not } \\
\text { Vaccinate } \\
(n=112) \\
\mathrm{N}(\%)\end{array}$ & $p$-Value \\
\hline $\begin{array}{c}\text { Not detected } \\
\text { detected }\end{array}$ & $\begin{array}{c}180(95.2) \\
9(4.8)\end{array}$ & $\begin{array}{c}131(72.8) \\
5(55.6)\end{array}$ & $\begin{array}{c}49(27.2) \\
4(44.4)\end{array}$ & 0.458 & $\begin{array}{c}74(41.1) \\
3(33.3)\end{array}$ & $\begin{array}{c}106(58.9) \\
6(66.7)\end{array}$ & 0.908 \\
\hline
\end{tabular}

Note: A total of 161 of the respondents living with HIV did not detect or did not know their viral load.

Table 4. Hypothesis test results.

\begin{tabular}{|c|c|c|c|c|c|c|}
\hline Hypothesis & Path between & $\begin{array}{c}\text { Nonstandard } \\
\text { Coefficient }\end{array}$ & $\begin{array}{c}\text { Standardization } \\
\text { Coefficient }\end{array}$ & S.E. & C.R. & $p$ \\
\hline $\mathrm{H} 1$ & $\mathrm{PU} \rightarrow \mathrm{PR}$ & -1.049 & -0.857 & 0.147 & -7.137 & $* * *$ \\
\hline $\mathrm{H} 2$ & $\mathrm{PU} \rightarrow \mathrm{BI}$ & 0.074 & 0.055 & 0.306 & 0.242 & 0.809 \\
\hline $\mathrm{H} 3$ & $\mathrm{PR} \rightarrow \mathrm{BI}$ & -0.448 & -0.404 & 0.085 & -2.025 & 0.043 * \\
\hline $\mathrm{H} 4$ & $\mathrm{SN} \rightarrow \mathrm{BI}$ & 0.731 & 0.760 & 0.055 & 13.378 & $* * *$ \\
\hline H5 & $\mathrm{PBC} \rightarrow \mathrm{BI}$ & 0.063 & 0.090 & 0.033 & 1.878 & 0.060 \\
\hline H6 & $\mathrm{PBC} \rightarrow \mathrm{B}$ & 0.004 & 0.010 & 0.021 & 0.191 & 0.848 \\
\hline $\mathrm{H} 7$ & $\mathrm{BI} \rightarrow \mathrm{B}$ & 0.224 & 0.370 & 0.032 & 7.018 & $* * *$ \\
\hline
\end{tabular}

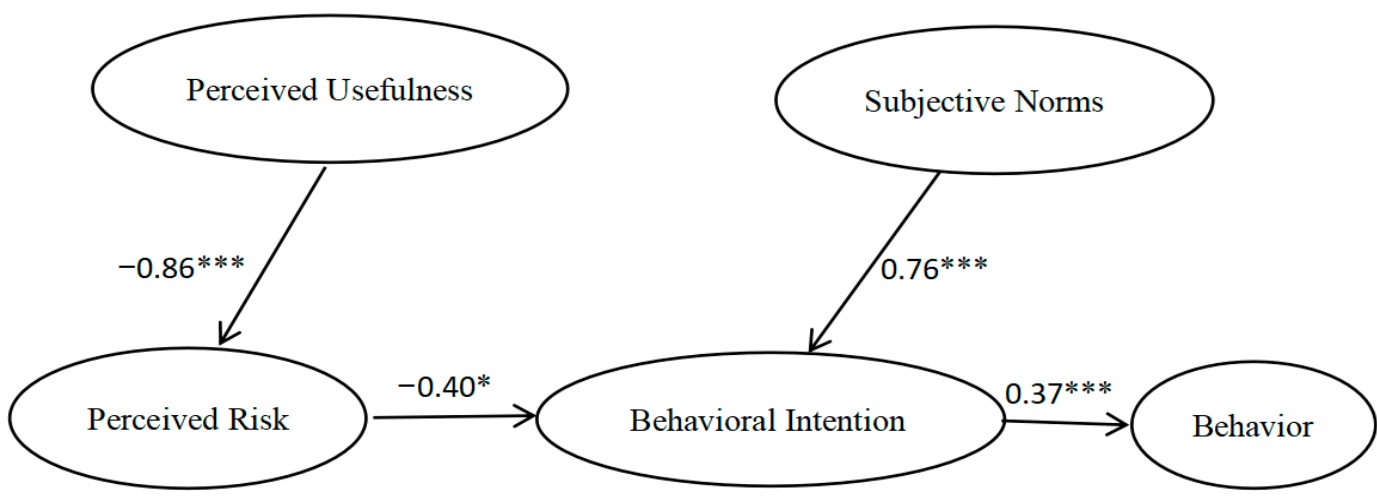

Figure 2. Results of deleting meaningless paths. Note: ${ }^{* * *} p<0.001{ }^{*} p<0.05$.

As shown in Table 5, PR fully mediated the effects of PU on BI, BI fully mediated the effects of PR on B, and BI fully mediated the effects of SNs on B.

Table 5. Mediating effect test.

\begin{tabular}{|c|c|c|c|c|c|c|c|c|c|c|c|}
\hline \multicolumn{3}{|c|}{ Mediation Path } & \multicolumn{8}{|c|}{ Mediating Effect } & \multirow{3}{*}{$\begin{array}{c}\text { Mediating } \\
\text { Effect }\end{array}$} \\
\hline \multirow{2}{*}{ IV } & \multirow{2}{*}{$\mathbf{M}$} & \multirow{2}{*}{ DV } & \multirow{2}{*}{$\begin{array}{l}\text { Effect } \\
\text { Value }\end{array}$} & \multirow{2}{*}{ SE } & \multicolumn{3}{|c|}{ Bias-Corrected $95 \%$ CI } & \multicolumn{3}{|c|}{ Percentile 95\% CI } & \\
\hline & & & & & Lower & Upper & $p$ & Lower & Upper & $p$ & \\
\hline PU & PR & BI & 0.405 & 0.099 & 0.225 & 0.612 & 0.001 & 0.226 & 0.613 & 0.001 & Full \\
\hline PR & BI & B & -0.177 & 0.044 & -0.271 & -0.100 & 0.001 & -0.264 & -0.095 & 0.001 & Full \\
\hline SN & $\mathrm{BI}$ & B & 0.287 & 0.061 & 0.161 & 0.396 & 0.001 & 0.155 & 0.394 & 0.001 & Full \\
\hline
\end{tabular}

Note: IV = independent variable; $\mathrm{M}$ = mediator; DV = dependent variable.

\section{Discussion}

The results showed that 153 respondents to the questionnaire (43.71\%) had been vaccinated against COVID-19. Previous studies on vaccination against COVID-19 in PLWH mainly reflected vaccination willingness and COVID-19 vaccine hesitancy. In one study, $28.7 \%$ of the participants declared their hesitancy about being vaccinated against 
COVID-19 [16]. More studies on vaccination intention have focused on the general population. A survey on the attitudes toward COVID-19 vaccination among the general population showed that $82.94 \%$ of the participants wished to be vaccinated, $14.73 \%$ of the participants were hesitant, and only $2.33 \%$ of the participants refused to be vaccinated [27]. A comparison between the data from these two studies suggested that there was a more serious phenomenon of vaccine hesitancy among PLWH. However, because these data came from different populations, it was impossible to conclude that the vaccine hesitation of PLWH was more serious than that of other groups. At present, COVID-19 vaccination is still in progress, the vaccination situation is still changing, and people's vaccination intentions and behavior will also continue to change.

We found that there were differences regarding vaccination intention and the COVID-19 vaccination status of the respondents according to age, gender, religious belief, marital status, income, education level, occupation, the duration of HIV diagnosis, the presence of other chronic diseases, the virus load detection, and the side effects of antiretroviral drugs, but these differences were not obvious $(p>0.05)$. However, until the end of the survey period, most research on COVID-19 vaccination had focused on vaccination attitudes. One Chinese study showed that vaccine refusal and vaccine hesitancy were not affected by age, marital status, income, or occupation but were dependent on gender and education level among residents in Guangzhou [8]. However, another recent Chinese study showed that vaccine hesitancy and vaccination refusal were associated with gender [27]. They found that women were more likely to be hesitant about vaccines [27-29]. The reasons for these gender differences are unclear. On the one hand, women generally pay more attention to their health, and their awareness of healthcare is higher than that of men [30]. On the other hand, the results might have been affected by regional differences and cultural differences [31-33]. In our study, there was no significant gender difference in vaccination behavior. This might be a result of the small number of female respondents included in our study. The vaccine behavior differences according to the duration of HIV diagnosis were not obvious $(p>0.05)$. This might be related to the effective drug control of PLWH. In our study, the intention to get vaccinated and the vaccination behavior toward COVID-19 were not shown to be associated with virus load. This might be related to the fact that only $54.0 \%$ of our participants knew their viral load, and fewer had had their viral load detected. The difference in vaccination intention among the general adult population between those who had been diagnosed with combined chronic diseases and those who had not was statistically significant [34]. However, we found that for PLWH, the difference in vaccination intention between those who had been diagnosed with other chronic diseases and those who had not was not statistically significant. This might be related to their HIV status, since they might be more concerned about HIV control. We also found that the differences in vaccination intention related to the side effects of taking antiretroviral drugs were not obvious $(p>0.05)$. Clinically, mild side effects can be eliminated without special treatment, moderate side effects can be controlled by symptomatic treatment, and clinicians will change the treatment scheme to reduce the impact of drug side effects when the drug side effects of PLWH are very serious. The lack of any obvious differences in vaccination intention here might be related to the controllable nature of the side effects of the drugs used by our participants.

Our results showed that PU had a negative effect on PR, PR had a negative effect on BI, SNs had a positive effect on BI, and BI had a positive effect on B. The PR of PLWH regarding COVID-19 vaccination played a mediating role between $\mathrm{PU}$ and $\mathrm{BI}$. This means that PU did not directly affect BI but affected BI through PR. Our results also showed that BI played a mediating role between PR and vaccination behavior. That is, PR did not directly affect vaccination behavior, but affected vaccination behavior through BI. These results are similar to those obtained in other studies, which have shown that risk perception is a critical determinant of behavioral intention and health behavior $[35,36]$. The time from research to use of the COVID-19 vaccine was short, and the vaccine has been approved for emergency use. However, long-term data on the vaccine's efficacy and safety still need to 
be continuously monitored [37]. Many people are still worried about the safety and side effects of the vaccine [38]. In an uncertain situation, people's behavioral choices tend to reduce the perceived risk rather than maximizing the perceived benefits [39]. Therefore, in the case of determining the safety of the COVID-19 vaccine, people will consider the effectiveness of the vaccine [40]. Therefore, information regarding the safety and side effects of vaccination should be presented in a timely fashion, and behavioral intention can be increased by reducing the perceived risk of the COVID-19 vaccination. Studies have shown that providing negative information about the COVID-19 pandemic can help to enhance the public's risk perception, which provides an opportunity to improve the overall COVID-19 vaccination rate [41].

We also found that BI plays a mediating role between $\mathrm{SNs}$ and vaccination behavior, but $\mathrm{PBC}$ does not affect $\mathrm{BI}$ or vaccination behavior. This means that $\mathrm{SNs}$ can influence the vaccination rate through behavioral intentions, but $\mathrm{PBC}$ does not affect $\mathrm{BI}$, nor does $\mathrm{PBC}$ affect vaccination behavior. The result of the mediating role of $\mathrm{BI}$ further confirms research on the theory of planned behavior (TPB), which holds that human behavior is not $100 \%$ voluntary, but is instead under control [20]. However, according to the TPB, PBC influences behavior directly and indirectly through BI. This conclusion has not been confirmed in our study. This may be related to the lack of data concerning COVID-19 vaccination among PLWH. During the clinical trials and administration of the COVID-19 vaccine, there was limited a amount of data on the usefulness and side effects of the vaccine among PLWH. In the absence of accurate data showing that COVID-19 vaccines are useful to PLWH, they are more concerned about the risk of vaccination. This affects their vaccination behavior through their behavioral intention. Therefore, more data on the usefulness and risks of the COVID-19 vaccine for PLWH are needed to improve the vaccination intention of PLWH and promote the vaccine.

\section{Limitations}

There were several limitations to this survey. Convenient sampling and snowballing were used in the survey, but random sampling was not conducted, which may have affected the representativeness of the research samples. For example, the ratio of male to female PLWH in the survey area was 11.9:1, with fewer women in the survey. This is the main defect of this study and one of the most important problems to be solved in our follow-up investigation. With the changes in COVID-19 and the continued promotion of the COVID19 vaccination, the awareness of and vaccination intention regarding the COVID-19 vaccine are also changing constantly. Therefore, the vaccination behavior of PLWH needs to be investigated at different stages of the COVID-19 pandemic.

\section{Conclusions}

Our evidence suggests that the behavioral intentions regarding COVID-19 vaccination among PLWH play a mediating role between the perceived risk, subjective norms, and vaccination behavior. The perceived risk plays a mediating role between the perceived usefulness and the behavioral intention. Therefore, scientific popularization should be strengthened to enhance the awareness and the perceived usefulness of the COVID-19 vaccine and reduce the perceived risk of the vaccine for PLWH, thus improving vaccination intention and vaccination behavior in order to achieve vaccine protection.

Author Contributions: L.Q., L.Y. (Li Yang), J.G., L.Y. (Lan Yu) and X.L. designed the study, sent out the electronic questionnaire, and checked the data. L.Y. (Li Yang) and J.G. conducted the statistical analysis. L.Q. wrote the first manuscript draft. All authors contributed to the interpretation of the data and editing of the manuscript. All authors have read and agreed to the published version of the manuscript.

Funding: This study was funded by the "Research Project of Nursing Discipline in Journal" of the Chinese Medical Association in 2019 (NO. CMAPH-NRI2019002) and by the "Economic and Social Development Project" of Liaoning Province (No. 2022lslybkt-062). 
Institutional Review Board Statement: The study was approved by the Ethics and Research Review Committee of Qiqihar Medical University in China ([2020]38). The date of approval was 31 December 2020.

Informed Consent Statement: Informed consent was obtained from all subjects involved in the study.

Data Availability Statement: The datasets generated during the current study are not publicly available but are available from the corresponding author on reasonable request.

Conflicts of Interest: The authors declare no conflict of interest.

$\begin{array}{ll}\text { Abbreviations } \\ \text { PLWH } & \begin{array}{l}\text { people living with HIV } \\ \text { behavior }\end{array} \\ \text { B } & \text { perceived usefulness } \\ \text { PU } & \text { perceived risk } \\ \text { PR } & \text { subjective norms } \\ \text { SNs } & \text { perceived behavior control } \\ \text { PBC } & \text { behavior intention }\end{array}$

\section{References}

1. Jin, Y.-M.; Wu, W.-X.; Xiang, W.; Wu, B.; Fu, Z.-W.; Wang, H.-M.; Wu, W.-X.; Su, Q.-J.; Wang, W.-L.; Feng, Y.-G.; et al. Strategy on coping with COVID-19 vaccine hesitancy. China Trop. Med. 2021, 21, 365-369.

2. Dil, S.; Dil, N.; Maken, Z.H. COVID-19 Trends and Forecast in the Eastern Mediterranean Region with a Particular Focus on Pakistan. Cureus 2020, 12, e8582.

3. Lobo, A.P.; Cardoso-Dos-Santos, A.C.; Rocha, M.S.; Pinheiro, R.S.; Bremm, J.M.; Macário, E.M.; Oliveira, W.K.; França, G.V.A. COVID-19 epidemic in Brazil: Where are we at? Int. J. Infect. Dis. 2020, 97, 382-385. [CrossRef]

4. Utamura, M.; Koizumi, M.; Kirikami, S. An epidemiological model considering isolation to predict COVID-19 trends in Tokyo, Japan: Numerical analysis. JMIR Public Health Surveill. 2020, 6, e23624. [CrossRef]

5. World Health Organization. Coronavirus Disease 2019 (COVID-19). Numbers at a Glance. Available online: https://www.who. int/emergencies / diseases / novel-coronavirus-2019 (accessed on 9 July 2021).

6. Moore, S.; Hill, E.M.; Dyson, L.; Tildesley, M.J.; Keeling, M.J. Modelling optimal vaccination strategy for SARS-CoV-2 in the UK. PLoS Comput. Biol. 2021, 17, e1008849. [CrossRef]

7. Robertson, E.; Reeve, K.S.; Niedzwiedz, C.L.; Moore, J.; Blake, M.; Green, M.; Katikireddi, S.V.; Benzeval, M.J. Predictors of COVID-19 vaccine hesitancy in the UK household longitudinal study. Brain Behav. Immun. 2021, 4, 41-50. [CrossRef]

8. Wang, Z.-W.; Li, Z.; Huang, H.-M.; Yang, Z.-C.; Lv, J.-C. Investigation on residents' awareness of COVID-19 vaccines and vaccination willingness in Guangzhou. Mod. Prev. Med. 2021, 48, 732-737.

9. Hursh, S.R.; Strickland, J.C.; Schwartz, L.P.; Reed, D.D. Quantifying the impact of public perceptions on vaccine acceptance using behavioral economics. Front. Public Health 2020, 8, 608852. [CrossRef]

10. Chung, J.Y.; Thone, M.N.; Kwon, Y.J. COVID-19 vaccines: The status and perspectives in delivery points of view. Adv. Drug Deliv. Rev. 2021, 170, 1-25. [CrossRef]

11. Stern, P.L. The changing face of vaccines and vaccination. Vaccine 2016, 34, 6653-6654. [CrossRef]

12. Storlie, C.B.; Pollock, B.D.; Rojas, R.L.; Demuth, G.O.; Johnson, P.W.; Wilson, P.M.; Heinzen, E.P.; Liu, H.; Carter, R.E.; Habermann, E.B.; et al. Quantifying the importance of COVID-19 vaccination to our future outlook. Mayo Clin. Proc. 2021, 96, 1890-1895. [CrossRef] [PubMed]

13. Bureau of Disease Control and Prevention of National Health Commission of the People's Republic of China. Technical vaccination recommendations for COVID-19 vaccines in China. JOL Chin. Viral Dis. 2021, 11, 161-162.

14. World Health Organization. HIV/AIDS Fact Sheet; World Health Organization: Geneva, Switzerland, 2020. Available online: https:/ / www.who.int/news-room/fact-sheets / detail/hiv-aids (accessed on 18 January 2021).

15. Mellor, M.M.; Bast, A.C.; Jones, N.R.; Roberts, N.W.; Ordóñez-Mena, J.M.; Reith, A.J.M.; Butler, C.C.; Matthews, P.C.; Dorward, J. Risk of adverse coronavirus disease 2019 outcomes for people living with HIV. AIDS 2021, 35, F1-F10. [CrossRef] [PubMed]

16. Vallée, A.; Fourn, E.; Majerholc, C.; Touche, P.; Zucman, D. COVID-19 vaccine hesitancy among french people living with HIV. Vaccines 2021, 9, 302. [CrossRef]

17. Rahimi, B.; Nadri, H.; Lotfnezhad, A.H.; Timpka, T. A systematic review of the technology acceptance model in health informatics. Appl. Clin. Inform. 2018, 9, 604-634. [CrossRef] [PubMed]

18. Mailizar, M.; Burg, D.; Maulina, S. Examining university students' behavioural intention to use e-learning during the COVID-19 pandemic: An extended TAM model. Educ. Inf. Technol. 2021, 8, 1-21. 
19. Jaspal, R.; Breakwell, G.M. Social support, perceived risk and the likelihood of COVID-19 testing and vaccination: Cross-sectional data from the United Kingdom. Curr. Psychol. 2021, 8, 1-13.

20. Germani, A.; Buratta, L.; Delvecchio, E.; Gizzi, G.; Mazzeschi, C. Anxiety severity, perceived risk of COVID-19 and individual functioning in emerging adults facing the pandemic. Front. Psychol. 2020, 11, 567505. [CrossRef]

21. Ajzen, I. The theory of planned behavior. Organ. Behav. Hum. Decis. Process. 1991, 50, 179-211. [CrossRef]

22. La Barbera, F.; Ajzen, I. Control interactions in the theory of planned behavior: Rethinking the role of subjective norm. Eur. J. Psychol. 2020, 16, 401-417. [CrossRef] [PubMed]

23. Lim, J.Y.; Kim, G.M.; Kim, E.J. Predictors of entrepreneurial intention of nursing students based on theory of planned behavior. J. Multidiscip. Healthc. 2021, 14, 533-543. [CrossRef]

24. MacCallum, R.C.; Browne, M.W.; Sugawara, H.M. Power analysis and determination of sample size for covariance structure modeling. Psychol. Methods 1996, 1, 130-149. [CrossRef]

25. Browne, M.W.; MacCallum, R.C.; Kim, C.T.; Andersen, B.L.; Glaser, R. When fit indices and residuals are incompatible. Psychol. Methods 2002, 7, 403-421. [CrossRef] [PubMed]

26. Hu, L.; Bentler, P.M. Fit indices in covariance structure modeling: Sensitivity to underparameterized model misspecification. Psychol. Methods 1998, 3, 424-453. [CrossRef]

27. Wu, G.-W.; Deng, T.; Zhang, M.-Q.; Li, Z.-N.; Pu, W.-D.; Wang, J.-X. A survey on the attitudes towards COVID-19 vaccination and its'sociological and psychological influencing factors. Chin. J. Clin. Psychol. 2021, 29, 622-625.

28. Akarsu, B.; Canbay, Ö.D.; Ayhan, B.D.; Aksoy, H.; Fidanc1, İ.; Cankurtaran, M. While studies on COVID-19 vaccine is ongoing, the public's thoughts and attitudes to the future COVID-19 vaccine. Int. J. Clin. Pract. 2021, 75, e13891. [CrossRef] [PubMed]

29. Ward, J.K.; Alleaume, C.; Patrick, P.W.; The COCONEL Group. The French public's attitudes to a future COVID-19 vaccine: The politicization of a public health issue. Soc. Sci. Med. 2020, 265, 113414. [CrossRef]

30. Sun, S.; Lin, D.; Operario, D. Interest in COVID-19 vaccine trials participation among young adults in China: Willingness, reasons for hesitancy, and demographic and psychosocial determinants. Prev. Med. Rep. 2021, 22, 101350. [CrossRef]

31. Fisher, K.A.; Bloomstone, S.J.; Walder, J.; Crawford, S.; Fouayzi, H.; Mazor, K.M. Attitudes toward a potential SARS-CoV-2 vaccine: A survey of U.S. Adults Ann. Intern. Med. 2020, 173, 964-973. [CrossRef]

32. Neumann-Böhme, S.; Varghese, N.E.; Sabat, I.; Barros, P.P.; Brouwer, W.; van Exel, J.; Schreyögg, J.; Stargardt, T. Once we have it, will we use it? A European survey on willingness to be vaccinated against COVID-19. Eur. J. Health Econ. 2020, 21, 977-982. [CrossRef] [PubMed]

33. Dror, A.A.; Eisenbach, N.; Taiber, S.; Morozov, N.G.; Mizrachi, M.; Zigron, A.; Srouji, S.; Sela, E. Vaccine hesitancy: The next challenge in the fight against COVID-19. Eur. J. Epidemiol. 2020, 35, 775-779. [CrossRef]

34. Shmueli, L. Predicting intention to receive COVID-19 vaccine among the general population using the health belief model and the theory of planned behavior model. BMC Public Health 2021, 21, 804. [CrossRef]

35. Liu, Y.; Wang, R.; Huang, R.; Cao, Y.; Wang, J.; Feng, D. Influencing factors and their relationships of risk perception and decision-making behaviour of polypharmacy in patients with chronic diseases: A qualitative descriptive study. BMJ Open 2021, 11, e043557. [CrossRef]

36. Ferrer, R.; Klein, W.M. Risk perceptions and health behavior. Curr. Opin. Psychol. 2015, 5, 85-89. [CrossRef] [PubMed]

37. Singh, J.A.; Upshur, R.E.G. The granting of emergency use designation to COVID-19 candidate vaccines: Implications for COVID-19 vaccine trials. Lancet Infect. Dis. 2021, 21, e103-e109. [CrossRef]

38. Wentzell, E.; Racila, A.M. The social experience of participation in a COVID-19 vaccine trial: Subjects' motivations, others' concerns, and insights for vaccine promotion. Vaccine 2021, 39, 2445-2451. [CrossRef] [PubMed]

39. Byrne, K.A.; Six, S.G.; Anaraky, R.G.; Harris, M.W.; Winterlind, E.L. Risk-taking unmasked: Using risky choice and temporal discounting to explain COVID-19 preventative behaviors. PLoS ONE 2021, 16, e0251073. [CrossRef] [PubMed]

40. Wouters, O.J.; Shadlen, K.C.; Salcher-Konrad, M.; Pollard, A.J.; Larson, H.J.; Teerawattananon, Y.; Jit, M. Challenges in ensuring global access to COVID-19 vaccines: Production, affordability, allocation, and deployment. Lancet 2021, 397, 1023-1034. [CrossRef]

41. Guoming, Y.; Ya, Y.; Xuejiao, C. Cognition, willingness and influencing factors of vaccination among residents in China from the perspective of platform. J. Mass Commun. Mon. 2021, 7, 64-72. 